\title{
Acquisition Integration Flexibility. Toward a Conceptual Framework
}

\begin{tabular}{|r|l|}
\hline Journal: & Journal of Strategy and Management \\
\hline Manuscript ID & JSMA-05-2018-0049.R1 \\
\hline Manuscript Type: & Conceptual Paper \\
\hline Keywords: & Acquisitions, Merger, Integration, Flexibility, Capabilities, Performance \\
\hline \multicolumn{2}{|l}{} \\
\hline
\end{tabular}

SCHOLARONE ${ }^{\text {m }}$

Manuscripts 


\section{ACQUISITION INTEGRATION FLEXIBILITY: A CONCEPTUAL FRAMEWORK}

Conducting acquisitions constitutes an established strategy in dynamic markets (Zajac et al., 2000; Vermeulen and Barkema, 2001; Heeley et al., 2006). Acquisitions can both initiate and adjust to change in a firm's competitive environment (Keil et al., 2013; Haleblian et al., 2012) by providing an acquirer with access to new competencies or markets faster and at a lower cost than organic growth (Capron, 1999; Lee \& Lieberman, 2010; Makri et al., 2010; Calipha et al., 2018). Still, acquisitions often fail to produce value to shareholders (King et al., 2004), or even destroy value (Moeller et al., 2005), and acquiring firm shareholders typically experience losses (Andrade et al., 2001). While research suggests that extracting the full benefits of an acquisition generally requires careful planning for organizational integration between the involved firms (Brueller et al., 2017; Graebner et al., 2017; Haspeslagh and Jemison, 1991; Lubatkin et al., 1998; Steigenberger, 2017), theory remains incomplete with how firms manage unpredicted events during integration.

While the difficulty of fully predicting events is foundational to integration research (Jemison and Sitkin, 1986), research has emphasized the benefits of integration planning to better foresee, avoid, and master integration challenges (Ahammad and Glaister, 2013).

Arguably, the focus on planning has come at the expense of theorizing on how to manage inevitable adjustments during integration. For example, research shows that internal employee anxiety and stress evolve in ways difficult to predict (Schweiger and DeNisi, 1991; Dackert et al., 2003). Further, integration can lead to tensions between cultures that are inherently hard to decipher (Stahl and Voigt, 2008) and give rise to hard to predict in-group and out-group biases associated with political behavior (Jetten et al., 2002; van Leeuwen et al., 2003). At the same time, external dynamism involves efforts intended to surprise acquirers including competitive reactions (King and Schriber, 2016), including unexpected losses of customers 
(Anderson et al., 2001; Öberg et al., 2007; Rogan and Greve, 2014) and employees (Brown et al., 2003), or both (Kato and Schoenberg, 2014). Further, integration takes several years to complete, making initial planning increasingly difficult and demanding of managerial attention at the expense of consideration of the external environment (Birkinshaw et al., 2000; Cording, Christmann and King, 2008; Larsson and Finkelstein, 1999). Alongside the ability to foresee events, we propose the ability to adjust to unforeseen events during integration is an underappreciated explanation in research for acquisition performance.

In light of the limited structured attention to how firms detect and mitigate the effects of dynamism during integration on acquisition performance, we develop the role of integration flexibility as a mediator of acquisition performance and demonstrate how this capability varies across firms. We build our framework on a dynamic capabilities perspective (Eisenhardt and Martin, 2000) and acquisition research with an emphasis on the role of managers at various hierarchical levels (Larsson and Finkelstein, 1999; Cording et al., 2008). Our basic argument is consistent with the realization that managers display bounded rationality (Cyert and March, 1963; Birkinshaw et al., 2000), and recognition that the impact of dynamism is mediated by organizational flexibility (cf. Hedberg et al., 1976; Helfat and Peteraf, 2009). We expect integration flexibility develops gradually and depends on an acquirer's organizational characteristics, deal characteristics, and the nature of internal and external change during integration.

Multiple contributions result from the paper. First, we develop the concept of integration flexibility. Specifically, we build on and extend related research (e.g., Junni et al., 2015 ) to develop this concept as an organization's ability to make appropriate adjustments to ongoing integration in relation to changing conditions. Second, we relate our observations to different acquisition phases or times managers and organizations can develop, assess, and apply integration flexibility. This implies an ability to adapt acquisition integration to 
dynamic conditions requires a process perspective (Jemison and Sitkin, 1986; Steigenberger, 2017). Third, our study adds a dimension to typical research considerations focused on the planning stage to consider implementation. As a result, our study emphasizes the need in acquisition research to also pay attention to acquirer capabilities for integration. Fourth, our paper strengthens the tie between dynamic capability and acquisition research. Specifically, prior research has established capabilities allow important variation in routine behavior (Heimeriks et al., 2012), and we elaborate the role of flexibility in variation. In the following sections, we develop a framework and related propositions for characteristics associated with integration flexibility.

\section{Benefits from Integration Flexibility}

Research has emphasized the complexity of acquisitions and that it is very difficult to predict integration (Vester, 2002), and we propose integration flexibility constitutes an important yet underestimated organizational capability. Generally, organizational flexibility involves the ability to adjust an organization to novel circumstances, involving the development of alternative strategies and attending to external change for maintaining strategic fit of an organization with its environment (Brozovic, 2018). In the context of acquisitions, we define integration flexibility as the capability to adapt planned and ongoing integration efforts to new conditions. Adaptation includes reducing or increasing the degree of integration, or shifting the aim of integration to benefit from other value sources than initially planned. The associated capability is largely tied to managers along the hierarchy who initiate, control, and adjust integration in both acquirer and target (Graebner, 2004; Cording et al., 2008; Lamont et al., 2018), and this likely impacts acquisition performance in several associated ways.

First, in acquisitions, synergy potential relates to increased competitiveness from integration between the involved firms, but anticipated synergies can disappear because of 
contextual change (Rouzies et al., 2018). Without adjustment, integration likely suffers for several reasons. First, integration creates costs and, if not matched with associated benefits, performance will fall. Second, insufficiently adjusted integration will leave potential value unrealized when conditions and synergies shift. Third, continued implementation of initial plans rendered obsolete by change will lead to reduced rather than improved performance. For example, the pursuit of cost reductions can leave an organization unable to cope with novel environmental conditions (Shaver, 2006).

Our starting point is that important drivers of acquisition flexibility are already discussed in acquisition research; however, they have not yet been combined in a discussion about how acquiring firms are able to adjust to unexpected events. Rather than evolving in a haphazard way, we argue that important variables from acquisition research can be structured logically to explain integration flexibility. Research generally agrees acquisitions evolve depending the acquirer, the target, and the integration process (Haspeslagh and Jemison, 1991; Bauer and Matzler, 2014), and we argue acquirer and target firm characteristics and integration management connects the most important factors addressed so far in acquisition research contributing to integration flexibility.

Therefore, we discuss three key factors taking center stage in acquisition research that combine and contribute to integration flexibility. First, integration flexibility depends on acquiring firm characteristics (Wright and Snell, 1998) that develop path-dependently and influenced by managerial choices and the situations to which the firm is exposed. Second, the effect of integration flexibility is affected by the context. Research consistently demonstrates a variety of contingencies affect acquisition performance, including the amount of acquirertarget similarity (relatedness) as a determinant of integration (e.g., Capron, 1999) and relative size (e.g., Graebner, 2004). As a result, we argue that deal characteristics modify the impact of integration flexibility. Third, integration research places great emphasis on the role of 
integration management (Cording et al., 2008), and the ability for integration flexibility associated with the resources applied to manage the integration process. Overall, the antecedents to integration flexibility explain the ability of acquiring firms to adjust ongoing integration processes that we develop in more detail below.

\section{Acquirer Characteristics}

The ability of acquiring firms to adjust ongoing integration processes following an acquisition is contingent on prior decisions and experiences. The ability to adjust to unexpected events is recognized especially in the dynamic capabilities perspective (Teece, Pisano and Shuen, 1997) as a means of explaining firm performance in environments of varying degrees of dynamism (Danneels, 2011) including acquisitions (Heimeriks et al., 2012). Although this broad research spans various approaches, we join the view that dynamic capabilities consist of collective, skill-based and purposeful organizational efforts of various complexity, repetition (Eisenhardt and Martin, 2000) and managerial intervention (Teece, 2012). Importantly, while distinct from luck (Winter, 2003), capabilities allow firms to "vary in how well they can perform an activity" (Helfat and Winter, 2011: 1244). It is the aim of capabilities research to identify what constitutes strategically important capabilities. In the context of knowledge transfer in acquisitions, Junni and colleagues (2015) propose sensing, resource fluidity, and collective commitment support this ability, and we argue this extends integration more broadly. In the following subsections, we develop how acquisition research provides several arguments overlapping with dynamic capabilities and integration flexibility.

Acquisition Experience. Acquisition experience contributes to an organizational ability that provides a portfolio of responses to circumstances that recognizes changing conditions and adapts initial plans. Research supports that acquisition experience enables drawing conclusions from prior deals to improve performance of subsequent transactions (Zollo and Singh, 2004). For example, experience can attenuate negative effects of superstitious learning 
(Zollo, 2009) to enable developing a variety of potential solutions (Haunschild and Sullivan, 2002). However, research also points to the risk of misapplying prior, similar experiences in new contexts (Ellis et al., 2011; Heimeriks et al., 2012). In other words, firms with too narrow experience may display lower performance in subsequent acquisitions. Simply, this ability is more likely in organizations with relevant experience in acquisition integration, as experienced acquirers can extract, accumulate, and create knowledge (Echajari and Thomas, 2015). Thus, we propose:

Proposition 1: Broader acquisition experience is positively associated with integration flexibility.

Resource slack. Organizational change typically requires preparation and costly alterations alongside ongoing operations that make slack important to flexibility. Slack compromises human, financial, or other resources not fully utilized in the daily operations of a firm that are associated with adaptation (Bourgeois, 1981; Singh, 1986). Research suggests that slack enables absorbing adjustment to internal and external change (Chattopadhyay et al., 2001; Damanpour, 1991). As a result, slack enables pursuing new, untested activities that are associated with adjusting to change (Danneels, 2002). This is consistent with slack being beneficial during disruptions (Wan and Yiu, 2009), and acquisitions are disruptive. Integration is also costly and greater slack available places fewer restrictions on adjusting integration plans. Shaver (2006) elaborates this point eloquently by arguing that acquisitions pursuing strict cost reduction risk reducing slack to make a firm vulnerable to sudden environmental shifts. As a result, we propose:

Proposition 2: Slack resources (e.g., financial) are positively associated with integration flexibility.

Middle Manager Involvement. The degree to which decision-making is centralized or dispersed differs between firms, and we posit this is related to integration flexibility. The formal and informal organizational impact on decision-making in firms is recognized both 
generally and in relation to dynamic capabilities to relate to their ability to adjust to external dynamism (Danneels, 2011; Kay, 2010), and we argue this in turn sets important boundaries for integration flexibility. While the role of middle managers is largely unexamined in acquisition research (Meglio and Risberg, 2010), it is recognized that middle managers face difficult circumstances during an acquisition (Meyer and Altenborg, 2008) at the same time they are critical to its success (Larsson and Finkelstein, 1999). Middle managers are closer to the challenges facing an organization and display less lock-in, but they also often have less authority to direct change (Nohria and Berkley, 1994; Sayles and Stewart, 1995). The more responsibility and authority a firm delegates to middle management the faster the firm can react and implement change (King et al., 2001; Stensaker et al., 2008). This suggests that greater middle management involvement can make a firm more flexible, and we propose:

Proposition 3: More middle management involvement in an acquiring firm is positively associated with integration flexibility.

Acquirer Dynamism Experience. Firm experience shapes the capabilities that develop, and firms in some industries face conditions more favorable for developing skills related to flexibility. While some sources of external dynamism are common to several markets, such as financial crises, other sources differ between industries. For instance, immature and fragmented markets often lack product standards and greater rivalry (Porter, 1980). Firms in such industries are more likely to experience dynamism associated with conditions needed to develop routines for managing change (Helfat and Peteraf, 2009). Therefore, firms operating in a dynamic industry is more likely to have managers with relevant experience in how to adapt to changing conditions. As a result, firms in dynamic industries will likely be able to extend their experience to change integration plans, when compared to managers from stable or more mature industries (cf. Spender, 1989). This is important since the success of alterations in integration plans likely depends on the inherent responsiveness of an acquiring 
firm (Volberda, 1996). Further, firms unable to adjust to environmental dynamism are likely to be outcompeted making remaining firms more likely to possess flexibility to accommodate industry dynamism. Therefore, we propose:

Proposition 4: Acquiring firm experience of industry dynamism is positively associated with integration flexibility.

\section{Deal Characteristics}

Research is consistent in pointing to the combination between acquirer and target as central to explain how acquisitions evolve. Often described in terms of 'fit', how the target relates to the acquirer sets important conditions for value potentials (Bauer and Matzler, 2014). While not acknowledged as such, we argue that several factors found in prior research also have important implications for integration flexibility. Put differently, the same acquirer can experience very different levels of flexibility in relation to two different targets. Put differently, acquisitions differ, and target firms contextualize and modify available integration flexibility.

Target Firm Size. While there is a risk that smaller targets are neglected (Calipha et al, 2010), smaller targets are more easily integrated (Cording et al., 2008). Given a similar level of integration, a larger target will require more effort to integrate (Pablo, 1994) as size correlates with increased rigidity and inertia (Hannan and Freeman, 1984). For example, the number of contacts that are possible between separately identifiable units grows exponentially as size increases linearly. The larger the total number of connections necessary for a desired level of integration drives greater disruption to the operations of both firms. Additionally, larger peer-groups of target and acquirer employees might trigger conflict (Homburg and Bucerius, 2006). Further, firm size affects legal constraints, as government oversight and regulations, such as employee protection increase with firm size. Overall, larger targets will receive more managerial attention than the smaller counterparts (Slangen, 2006), and we propose: 
Proposition 5: A target firm's size lowers acquirer integration flexibility.

Degree of integration. The degree of relatedness between an acquiring and target firm influences the degree of integration with related acquisitions typically requiring greater integration (Haspeslagh and Jemison, 1991; Pablo, 1994). We argue that the lower the intended integration level, the higher the integration flexibility. Primarily, less integration requires lower resource commitment, including managerial and financial resources. Greater integration contributes to managers having an internal focus that reduces perception of external cues (Cording et al., 2008) that can signal a need to adjust integration. Additionally, greater integration between combining firms increases the costs of reversing decisions and organizational links. As a result, greater integration carries a higher cost to respond to dynamic change, and we propose:

Proposition 6: Lower levels of integration positively influence integration flexibility. Physical Distance. Geographic distance has a persistent effect in selecting acquisition targets, and one explanation is the amount of information needed for integration is easier for more proximate target firms (Chakrabarti and Mitchell, 2013; Coval and Moskowitz, 1999). Greater distance also increases the opportunity for misunderstanding due to regional, cultural or institutional differences (Ahammad et al., 2016). For example, one of the rules applied by Cisco, an active acquirer, involves selecting geographically close targets, as Cisco's CEO is attributed to having the attitude that he did not want to have to board a plane to solve problems with an acquisition (Bunnell, 2000: 68). This argument is strengthened in cases where distance involves cultural or national borders (Bauer et al., 2018; Kling et al., 2014). Less physical distance between an acquirer and target $a l$ so facilitate knowledge flow from increased interaction between employees (Rosenkopf and Almedia, 2003), while increased distance is associated with higher transaction costs (McCarthy and Aalbers, 2016). Greater communication and face-to-face meetings over time are also associated with improved 
identification and trust (Lewicki and Bunker, 1995). The combined effect is that geographic proximity increases the amount of interactions, information exchanged and trust between combining firm employees that will likely facilitate change during integration. Thus, we propose:

Proposition 7: Greater physical distance between an acquirer and target negatively impacts integration flexibility.

\section{Integration management}

Acquisition research consistently points to the importance of how integration is managed for explaining acquisition performance (e.g., Capron, 1999; Cording, et al., 2008). Several decisions regarding how integration is managed are distinct from the acquiring firm organization and target. Very different acquirers can decide to focus on similar issues, and vice versa (Ellis and Lamont, 2004). The implication is that integration processes, or the focus of attention and resources are assigned to integration offer important insights into how acquisitions evolve. Although integration research covers a wide range of topics, below we focus on those most clearly connecting to integration flexibility during integration.

Environment Scanning. One condition for successful integration flexibility involves detecting changes to enable adjustment. Environmental scanning takes effort, as decisionmakers have an uncertain view of their competitive environment (Porac and Thomas 1990) and cognitive limitations contribute to routinized behavior (Cyert and March, 1963).

However, effort offers rewards, as firms that dedicate employees to environmental scanning have an increased chance to both detect and correctly interpret environment shifts (Elenkov, 1997). Still, it is often difficult to maintain environmental scanning during acquisition integration.

The time consuming nature of integration leads managers to focus internally at the expense of environmental scanning (Cording et al., 2008). A tendency to focus internally is 
likely compounded by managers viewing internal acquisition risks as easier to manage than external risks (Elango et al., 2013), contributing to managers overlooking externally driven needs to change (Graetz and Smith, 2010). Overall, we anticipate environmental scanning is more important during acquisition integration, as integration is among the best of times to attack competitors that are otherwise distracted (Meyer, 2008). Therefore, we propose:

Proposition 8: Environment scanning positively correlates integration flexibility. Integration Team Diversity. Research suggests that transition teams enable integration flexibility (Meglio et al., 2015). One important aspect of integration flexibility involves having an integration team with varied expertise. The ability to successfully bring in additional resources and adjust plans is contingent on the ability to correctly "read" internal and external events and interpret the consequences (Shaver, 2006). The ability to interpret complex processes relates to familiarity, and different training and career paths develop unique perspectives between organizational functions that influences the salience of information (Sorensen, 1999). The implication is that managers with a production background tend to emphasize issues relating to production, at the expense of information or cues perceived as more relevant to other functions that could be more important to acquisition success. During acquisition integration, adaptation depends on different managerial skills and experience, including familiarity with a target firm (Graebner, 2004; Krishnan et al., 1997). This does not mean a team has needed capacity, but expertise to recognize what is needed and when. For example, consultants can provide needed expertise and meet temporary increases in demand for specialized personnel (Feldman and Spratt, 1999). Therefore, we propose:

Proposition 9: An integration team's diversity positively correlates with integration flexibility.

Management Capacity. Implementing changes during integration increases manager workload and absorbs their attention (Kavanagh and Ashkanasy, 2006). Successful acquirers 
often maintain additional employees than expected for a final end state to avoid a negative impact on operations (Meyer, 2008). Research recognizes that acquisitions limit the ability of managers to coordinate diverse activities (Zhou, 2011), and, when overwhelmed by demands, managers likely go with what they know leading to locally rational decision making that negatively effects overall performance (Laamanen and Keil, 2008). Acquisition integration requires non-routine decisions and limited information that drives managerial sensemaking at the same time managers provide guidance to employees (e.g., Maitlis, 2005). A firm's ability to engage employees likely depends on managers being able to address increased demands during integration. Overall, greater management capacity will ease integration by enabling flexibility in its implementation, so we propose:

Proposition 10: Managerial capacity positively correlates with integration flexibility. Integration Speed. Speed is an important consideration for acquisition integration (Bauer and Matzler, 2014; Cording et al., 2008; Haspeslagh and Jemison, 1991). Research generally advises faster integration to reduce employee uncertainty, give competitors less time to respond, and realize performance improvement faster (Angwin, 2004; Homburg and Bucerius, 2006). However, integration decisions once made can be difficult to reverse (Leiblein et al., 2002), and research recognizes that integrating a target firm too fast risks destroying value (Angwin, 2004). For example, Uzelac and colleagues (2016) find that intuitive decision making combined with fast human integration reduces acquisition performance, and this may be partially attributed to increased turmoil. Additionally, the complexity of acquisition integration often drives active experimentation to achieve goals (Vester, 2002), and it is reasonable to expect this takes time. Therefore, we propose: Proposition 11: Faster integration is negatively associated with integration flexibility. Acquisition Performance 
While the benefits of integration flexibility likely remain insignificant in completely predictable or stable integration processes, we anticipate a positive impact under dynamic conditions. Primarily, strategic complexity makes planning difficult at the same time that it increases the need for planning (Kukalis, 1989). Acquisition integration is among the most complex activities managers face, and the primary benefit of having an initial integration plan is that it identifies what is important and provides a basis for adjustment. For example, initial analysis will make assumptions about acquisition integration with respect to competitor reactions, employee turnover, and other metrics that can be observed and significant deviations from expectations lead to the need to react (cf. Gates and Very, 2003; King and Schriber, 2016).

A related reason is that the process of implementation often focuses on additional planning (Stensaker et al., 2008). The amount of information known about a target firm will be limited during due diligence when initial integration plans are formed by an acquiring firm's managers. The increased interaction between acquiring and target firm managers will lead to the exchange of additional information that can lead to unexpected gains (Graebner, 2004). A positive impact of integration flexibility also relates to explicit plans limiting managerial options for reaching desired goals (Eisenberg and Witten, 1987), or it leaves ambiguity (Risberg, 2003). The combined implication is that integration flexibility can be an important part of integration planning, and the impact will be larger when dynamism is high. Therefore, we propose:

Proposition 12: The positive impact from integration flexibility on acquisition performance is contingent on the level of internal and external dynamism a firm faces.

\section{Discussion}

While acquisitions help firms adjust to market dynamism and changing conditions (Almor et al., 2014), research largely assumes a stable environment for integration. However, 
integration typically takes several years to complete and we build on research demonstrating convincingly such changes are difficult to predict. As a result, we meet a need to develop how firms maintain flexibility during acquisition integration. Consistent with a dynamic capabilities perspective, we develop factors that influence a capability for integration flexibility and its subsequent influence on acquisition performance. As a result, integration flexibility represents an important organizational ability that enables altering integration plans to achieve positive outcomes. Further, integration flexibility likely varies between firms, and this variation begins to explain variance in acquisition performance. We summarize our hypotheses in a framework. Figure 1 depicts our view of integration flexibility as an organizational ability with its determinants and influence on acquisition performance, and we next outline its theoretical and practical implications.

----- Insert Figure 1 about here -----

\section{Research Implications}

We complement a planning perspective in acquisition research to show that integration flexibility can result in improved acquisition performance. Research has established the importance of target assessment and acquisition planning, and, when planning is insufficient or difficult, acquisition performance suffers (Ahammad and Glaister, 2013). More recently, attention on the need to attend to uncertainty during integration has grown (e.g., Junni et al., 2015). We develop and extend this logic by showing that integration flexibility needs to accommodate changing conditions that are often difficult or impossible to predict, and we outline the factors constituting this capability. This complements prior deal-based planning frameworks that emphasizes the need to assess a target firm to initiate relevant integration efforts (e.g. Haspeslagh and Jemison, 1991). A clear implication is that integration flexibility 
is likely to affect the variables commonly studied in acquisition research, and it could begin to explain inconsistent results in predicting acquisition performance (King et al., 2004). Put differently, integration flexibility stands out as a novel explanation for why acquisition performance varies.

Capabilities develop over time, and we outline different organizational factors that influence the development of integration flexibility. Specifically, we outline integration flexibility across broad categories and times related to acquirer and deal characteristics, and integration management. This complements a process perspective of acquisition research (Jemison and Sitkin, 1986), and, while acquisition research still often considers these issues separately (Bauer and Matzler, 2014), our framework integrates them. This places integration flexibility as an intermediate ability in the acquisition process that influences acquisition performance (e.g., Cording et al., 2008).

Our framework adds a dimension to research on target selection that typically stresses financial viability and overpayment and benefits of different degrees of relatedness. For example, research suggests that acquirers are more likely recognize the benefit of combinations in related acquisitions that can be difficult for others to anticipate (cf. Winter, 2000) compared to acquisitions in unrelated industries (Graebner, 2004). Complementing such considerations, our framework provides needed research attention to integration flexibility. As this capability can differ between firms and each acquisition modifies the need for integration capability, we expand research on pre-acquisition assessment to consider a new set of factors necessary for successfully integrating a particular target. These insights collectively constitute a step toward new theory that can begin to explain inconsistent research findings on acquisition performance (e.g. King et al., 2004), and we attribute importance to them since acquisitions tend to occur in periods of industry restructuring where unexpected dynamism is typically high (Heeley et al., 2006). 
Finally, we strengthen and elaborate a link between research on firm capabilities and acquisitions. Prior research has established a firm's integration capability depends on prior experience (Heimeriks et al., 2012), and our framework expands it to consider conditions associated with a specific acquisition. This suggests that needed integration flexibility is partly contingent on acquiring firm characteristics or that integration capability is not subject to short-term planning. As such, integration flexibility is part of the set of capabilities acquiring firms can develop over time that have also been shown to impact acquisition performance (cf. Laamanen and Keil, 2008).

\section{Management Implications}

Our framework also has important consequences for acquiring managers. First, acquirers need to consider the integration capability, as this influences the likelihood of success. While planning integration remains important, our study emphasizes integration flexibility predicts acquisition performance in more realistic circumstances than the majority of research that assumes stable and predictable integration circumstances. Second, we outline factors that acquiring firms can influence to increase integration flexibility at different times of the acquisition process. An important implication is this capability depends partly on conditions long before a focal transaction. In consequence, we suggest managers not only plan a focal acquisition, but they also set aside resources for building integration flexibility needed to complete subsequent acquisitions. Lastly, integration flexibility is a capability that influences acquisition performance. Put differently, acquiring managers should go beyond financial considerations to consider whether available integration flexibility can support acquiring and integrating a prospective target.

\section{Limitations and Future Research}

We acknowledge that our research has multiple limitations. A central boundary condition for the relevance of our ideas is that integration flexibility assumes dynamism and uncertainty. 
While severely hampered in dynamic environments, traditional integration planning will likely be preferable in stable environments. Further, dynamic capabilities are also costly to develop and maintain (Winter, 2003), and the costs of integration may outweigh its benefits. We also anticipate negative impacts from excess integration flexibility are possible. For example, research has identified power games that develop during integration processes hinder reaching acquisition goals (Meyer and Altenborg, 2007), and continued adjustment to integration may unnecessarily extend integration and forming a common organizational identity. As a result, the climate and motivation for adjusting integration plans will be important. This study is limited to topics and factors studied in prior acquisition research, however, also allows us to point to areas of more research. Ours is a first instep into integrating previously fragmented insights into the need and possibilities for adjusting integration to unexpected dynamism, flexibility in acquisition integration and associated relationships with acquisition performance remain an important avenue for future research. To illustrate, we have built on research arguing for more research on external scanning, but also internal scanning during integration to detect upcoming challenges should be of value for explaining integration flexibility. 


\section{References}

Ahammad, M. F., Glaister and K. W. (2013), "The pre-acquisition evaluation of target firms and cross border acquisition performance", International Business Review, Vol. 22, pp. 894-904.

Ahammad, M. F., Tarba, S. Y., Liu, Y. and Glaister, K. W. (2016), "Knowledge transfer and cross-border acquisition performance: The impact of cultural distance and employee retention”, International Business Review, Vol. 25, pp. 66-75.

Almor, T., Tarba, S. and Margalit, A. (2014), "Maturing, technology-based, born-global companies: Surviving through mergers and acquisitions", Management International Review, Vol. 54, pp. 421-444.

Anderson, H., Havila, V. and Salmi, A. (2001), "Can you buy a relationship?: On the importance of customer and supplier relationships in acquisitions", Industrial Marketing Management, Vol. 30, pp. 575-586.

Andrade, G., Mitchell, M., and Stafford, E. (2001), "New evidence and perspectives on mergers", Journal of economic perspectives, 15, pp. 103-120.

Angwin, D. (2004), "Speed in M\&A Integration: The first 100 days", European Journal of Management, Vol. 22, pp. 418-430.

Bauer, F. and Matzler, K. (2014), "Antecedents of M\&A success: The role of strategic complementarity, cultural fit, and degree and speed of integration", Strategic Management Journal, Vol. 35, pp. 269-291.

Bauer, F., Schriber, S., Degischer, D. and King, D. R. (2018), “Contextualizing speed and cross-border acquisition performance: Labor market flexibility and efficiency effects", Journal of World Business, Vol. 53, pp. 290-301.

Birkinshaw, J., Bresman, H. and Håkanson, L. (2000), "Managing the post-acquisition integration process: How the human integration and task integration processes interact to foster value creation", Journal of Management Studies, Vol. 37, pp. 395-425.

Bourgeois L. (1981), "On the measurement of organizational slack", Academy of Management Review, Vol. 6, pp. 29-39.

Brown, C., Clancy, G. and Scholer, R. (2003), “A post-merger IS integration success story: Sallie Mae", MIS Quarterly Executive, Vol. 2, pp. 15-27.

Brozovic, D. (2018). "Strategic flexibility: A review of the literature", International Journal of Management Reviews, Vol. 20, pp. 3-31.

Brueller, N. N., Carmeli, A. and Markman, G. D. (2017), "Linking merger and acquisition strategies to postmerger integration: a configurational perspective of human resource management", Journal of Management, 0149206315626270.

Bunnell, D. (2000). Making the Cisco connection: The story behind the real internet superpower. New York: John Wiley \& Sons.

Calipha, R., Brock, D. M., Rosenfeld, A. and Dvir, D. (2018). “Acquired, transferred and integrated knowledge: a study of M\&A knowledge performance", Journal of Strategy and Management, Vol. 11 No. 3, pp. 282-305.

Calipha, R., Tarba, S. and Brock, D. (2010), Mergers and acquisitions: A review of phases, motives, and success factors. In: Cooper, C.L. and Finkelstein, S. (eds). Advances in Mergers \& Acquisitions, Vol. 9, pp. 1-24.

Capron, L. (1999), "The long-term performance of horizontal acquisitions", Strategic Management Journal, Vol. 20, pp. 987-1018.

Chakrabarti, A. and Mitchell, W. (2013), "The persistent effect of geographic distance in acquisition target selection", Organization Science, Vol. 24, pp. 1805-1826.

Chattopadhyay, P., Glick, W. and Huber, G. (2001), "Organizational actions in response to threats and opportunities", Academy of Management Journal, Vol. 44, pp. 937-955. 
Cording, M., Christmann, P. and King, D. (2008), "Reducing causal ambiguity in acquisition integration: Intermediate goals as mediators of integration decisions and acquisition performance", Academy of Management Journal, Vol. 51, pp. 744-767.

Coval, J. and Moskowitz, T. (1999), "Home bias at home: Local equity preference in domestic portfolios", Journal of Finance, Vol. 54, pp. 2045-2073.

Cyert, R. and March, J. (1963), A Behavioral Theory of the Firm. Englewood Cliffs, N.J.: Pentice Hall.

Dackert, I., Jackson, P., Brenner, S. and Johansson, C. (2003), "Eliciting and analysing employees' expectations of a merger", Human Relations, Vol. 56, pp. 705-725.

Damanpour, F. (1991), "Organizational innovation: A meta-analysis of effect of determinants and moderators", Academy of Management Journal, Vol. 34, pp. 555-590.

Danneels, E. (2002), "The dynamics of product innovation and firm competences", Strategic Management Journal, Vol. 23, pp. 1095-1121.

Danneels, E. (2011), "Trying to become a different type of company: Dynamic capability at Smith Corona", Strategic Management Journal, Vol. 32 No. pp. 1-31.

Echajari, L. and Thomas, C. (2015), "Learning from complex and heterogeneous experiences: the role of knowledge codification", Journal of Knowledge Management, Vol. 19, pp. 968986.

Eisenberg, E. and Witten, M. (1987), "Reconsidering openness in organizational communication", Academy of Management Review, Vol. 12, pp. 418-426.

Eisenhardt, K. M. and Martin, J. A. (2000), Dynamic capabilities: what are they? Strategic Management Journal, Vol. 21, pp. 1105-1121.

Elango, B., Lahiri, S. and Kundu, S. (2013), "How does firm experience and institutional distance impact ownership choice in high-technology acquisitions?", $R \& D$ Management, Vol. 43, pp. 501-516.

Elenkov, D. (1997), "Strategic uncertainty and environmental scanning: The case for institutional influences on scanning behavior", Strategic Management Journal, Vol. 18, pp. 287-302.

Ellis, K. and Lamont, B. (2004). "Ideal acquisition integration approaches in related acquisitions of equals: A test of long-held beliefs". In: Cooper, C.L. and Finkelstein, S. (eds). Advances in Mergers \& Acquisitions, Vol. 3, pp. 81-102.

Ellis, K.M., Reus, T.H., Lamont, B. T. and Ranft, A.L. (2011), "Transfer effects in large acquisitions: How size-specific experience matters", Academy of Management Journal, Vol. 54, No. 6, pp. 1261-1276.

Feldman, M. and Spratt, M. (1999). Five frogs on a log: A CEO's field guide to accelerating the transition in mergers, acquisitions and gut wrenching change. New York: Harper Collins.

Gates, S. and Very, P. (2003), "Measuring performance during M\&A integration", Long Range Planning, Vol. 36, pp. 167-185.

Graebner, M. (2004), "Momentum and serendipity: How acquired leaders create value in the integration of technology firms", Strategic Management Journal, Vol. 25, pp. 751-777.

Graebner, M. E., Heimeriks, K. H., Huy, Q. N. ans Vaara, E. (2017), “The process of postmerger integration: A review and agenda for future research", Academy of Management Annals, Vol. 11, pp. 1-32.

Graetz, F. and Smith, A. (2010), "Managing organizational change: A philosophies of change approach", Journal of Change Management, Vol. 10, pp. 135-154.

Haleblian, J., McNamara, G., Kolev, K. and Dykes, B. (2012), "Exploring firm characteristics that differentiate leaders from followers in industry merger waves: A competitive dynamics perspective”, Strategic Management Journal, Vol. 33, pp. 1057-1052. 
Hannan, J. and Freeman, J. (1989), Organizational Ecology. Harvard University Press: Cambridge MA.

Haspeslagh, P. and Jemison, D. (1991), Managing acquisitions: Creating value through corporate renewal. New York: Free Press.

Haunschild, P. and Sullivan, B. (2002), "Learning from complexity: Effects of prior accidents and incidents on airlines' learning", Administrative Science Quarterly, Vol. 47, pp. 609643.

Hedberg, B., Bystrom, P. and Starbuck, W. (1976), "Camping on seesaws: Prescriptions for a self-designing organization”, Administrative Science Quarterly, Vol. 21, pp. 41-65.

Heeley, M., King D. and Covin, J. (2006), "R\&D investment level and environment as predictors of firm acquisition", Journal of Management Studies, Vol. 43, pp. 1513-1536.

Heimeriks, K. H., Schijven, M. and Gates, S. (2012), "Manifestations of higher-order routines: The underlying mechanisms of deliberate learning in the context of postacquisition integration", Academy of Management Journal, Vol. 55, pp. 703-726.

Helfat, C. and Peteraf, M. (2009), "Understanding dynamic capabilities: progress along a developmental path", Strategic Organization, Vol. 7, pp. 91-102.

Helfat, C. E. and Winter, S. G. (2011), "Untangling dynamic and operational capabilities: Strategy for the (N) ever-changing world”, Strategic Management Journal, Vol. 32, pp. 1243-1250.

Homburg, C. and Bucerius, M. (2006), "Is speed of integration really a success factor of mergers and acquisitions?", An analysis of the role of internal and external relatedness. Strategic Management Journal, Vol. 27, pp. 347-367.

Jemison, D. B. and Sitkin, S. B. (1986), "Corporate acquisitions: A process perspective", Academy of Management Review, Vol. 11, pp. 145-163.

Jetten, J., Duck, J., Terry, D. J. and O'Brian, A. (2002), "Being attuned to intergroup differences in mergers: The role of aligned leaders for low-status groups", Personality and Social Psychology Bulletin, Vol. 28, pp. 1194-1201.

Junni, P., Sarala, R., Tarba, S. and Weber, Y. (2015), "The role of strategic agility in acquisitions", British Journal of Management, Vol. 26, pp. 596-616.

Kato, J. and Schoenberg, R. (2014), "The impact of post-merger integration on the customersupplier relationship", Industrial Marketing Management, Vol. 43, pp. 335-345.

Kavanagh, M. and Ashkanasy, N. (2006), "The Impact of Leadership and Change Management Strategy on Organizational Culture and Individual Acceptance of Change during a Merger", British Journal of Management, Vol. 17, pp. 81-103.

Kay, N. (2010), "Dynamic capabilities as context: the role of decision, system and structure", Industrial and Corporate Change, Vol. 19, pp. 1205-1223.

Keil, T., Laamanen, T. and McGrath, R. (2013), "Is a counterattack the best defense? Competitive dynamics through acquisitions", Long Range Planning, Vol. 46, pp. 195-215.

King, A., Fowler, S. and Zeithaml, C. (2001), "Managing organizational competencies for competitive advantage: The middle-management edge", Academy of Management Executive, Vol. 15, pp. 95-106.

King, D. and Schriber, S. (2016), "Addressing competitive responses to acquisitions", California Management Review, Vol. 58, pp. 109-124.

King, D., Dalton, D., Daily, C. and Covin, J. (2004), "Meta-analyses of post-acquisition performance: Indications of unidentified moderators", Strategic Management Journal, Vol. 25, pp. 187-200.

Kling, G., Ghobadian, A., Hitt, M. A., Weitzel, U., and O'Regan, N. (2014), ’The effects of cross-border and cross-industry mergers and acquisitions on home-region and global multinational enterprises", British Journal of Management, 25, pp. 32. 
Krishnan, H., Miller, A. and Judge, W. (1997), "Diversification and top management team complementarity: Is performance improved by merging similar or dissimilar teams?", Strategic Management Journal, Vol. 18, pp. 361-374.

Kukalis, S. (1989), "The relationship among firm characteristics and design of strategic planning systems in large organizations", Journal of Management, Vol. 15, pp. 565-579.

Laamanen, T. and Keil, T. (2008), "Performance of serial acquirers: Toward an acquisition program perspective", Strategic Management Journal, Vol. 29, pp. 663-672.

Lamont, B., King, D., Maslach, D., Schwerdtfeger, M. and Tienari, J. (2018), "Integration Capacity and Knowledge-Based Acquisition Performance", R\&D Management. doi.org/10.1111/radm. 12336

Larsson, R. and Finkelstein, S. (1999), "Integrating strategic, organizational, and human resource perspectives on mergers and acquisitions: A case survey of synergy realization", Organization Science, Vol. 10, pp. 1-26.

Lee, G. K. and Lieberman, M. B. (2010), “Acquisition vs. internal development as modes of market entry"' Strategic Management Journal, Vol. 31, pp. 140-158.

Leiblein, M., Reuer, J. and Dalsace, F. (2002), "Do make or buy decision matter? The influence of organizational governance on technological performance”, Strategic Management Journal, Vol. 23, pp. 817-833.

Lewicki R. and Bunker B. (1995), Trust in relationships: a model of development and decline. In: Conflict, Cooperation and Justice, Bunker B., Rubin J. (eds). Jossey-Bass: San Francisco, CA, pp. 133-173.

Lubatkin, M., Calori, R., Very, P. and Veiga, J. (1998), "Managing mergers across borders: A two-nation exploration of a nationally bound administrative heritage", Organization Science, Vol. 9, pp. 670-684.

Maitlis, S. (2005), "The social processes of organizational sensemaking”, Academy of Management Journal, Vol. 48, pp. 21-49.

Makri, M., Hitt, M. A. Lane, P. J. (2010), ”Complementary technologies, knowledge relatedness, and invention outcomes in high technology mergers and acquisitions", Strategic Management Journal, Vol. 31, pp. 602-628.

McCarthy, K. J. and Aalbers, H. L. (2016), "Technological acquisitions: The impact of geography on post-acquisition innovative performance", Research Policy, Vol. 45, pp. $1818-1832$.

Meglio, O. and Risberg, A. (2010), "Mergers and acquisitions - time for a methodological rejuvenation of the field?", Scandinavian Journal of Management, Vol. 26, pp. 87-95.

Meglio, O., King, D. and Risberg, A. (2015), "Improving acquisition performance with contextual ambidexterity", Human Resource Management, Vol. 54, pp. 29-43.

Meyer, C. (2008), "Value leakages in mergers and acquisitions: Why they occur and how they can be addressed", Long Range Planning, Vol. 41, pp. 197-224.

Meyer, C. and Altenborg, E. (2007), "The disintegrating effects of equality: A study of a failed international merger", British Journal of Management, Vol. 18, pp. 257-271.

Meyer, C. and Altenborg, E. (2008), "Incompatible strategies in international mergers: The failed merger between Telia and Telenor", Journal of International Business Studies, Vol. 39 , pp. 508-525.

Moeller, S. B., Schlingemann, F. P. and Stulz, R. M. (2005), "Wealth destruction on a Massive Scale: A study of Acquiring Firm Returns in the Merger Wave of the Late 1990s", Journal of Finance, Vol. 60, pp. 757-782.

Nohria, N. and Berkley, J. (1994), "Whatever happened to the take-charge manager?". Harvard Business Review, Vol. 72, pp. 128-137.

Öberg, C., Henneberg, S. and Mouzas, S. (2007), "Changing network pictures: Evidence from mergers and acquisitions”, Industrial Marketing Management, Vol. 36, pp. 926-940. 
Pablo, A. (1994), "Determinants of acquisition integration level: A decision-making perspective", Academy of Management Journal, Vol. 37, pp. 803-836.

Porac, J. and Thomas, H. (1990), "Taxonomic mental models in competitor definition", Academy of Management Review, Vol. 15, pp. 224-240.

Porter, M. (1980), Competitive Strategy: Techniques for analyzing industries and competitors. New York: Free Press.

Risberg, A. (2003), "Shared and multiple realities in acquisitions", Nordiske Organisasjonstudier, Vol 5, pp. 58-82.

Rogan, M. and Greve, H. (2014), "Resource dependence dynamics: Partner reactions to mergers", Organization Science, Vol. 26 pp. 239-255.

Rosenkopf, L. and Almedia, P. (2003), "Overcoming local search through alliances and mobility", Management Science, Vol. 49, pp. 751-766.

Rouzies, A., Colman, H. L. and Angwin, D. (2018), "Recasting the dynamics of postacquisition integration: An embeddedness perspective", Long Range Planning. In Press.

Sayles, L. and Stewart, A. (1995), "Belated recognition for work flow entrepreneurs: A case of selective perception and amnesia in management thought", Entrepreneurship Theory \& Practice, Vol. 19, pp. 7-23.

Schweiger, D. and Denisi, A. (1991), "Communication with employees following a merger: A longitudinal field experiment", Academy of Management Journal, Vol. 34, pp. 110-135.

Shaver, J. (2006), "A paradox of synergy: Contagion and capacity effects in mergers and acquisitions", Academy of Management Review, Vol. 31, pp. 962-976.

Singh, J. (1986), "Performance, slack, and risk taking in organizational decision making", Academy of Management Journal, Vol. 29, pp. 562-585.

Slangen, A. (2006), "National cultural distance and initial foreign acquisition performance: The moderating effect of integration", Journal of World Business, Vol. 41, pp. 161-170.

Sorensen, J. (1999), "Executive migration and interorganizational competition", Social Science Research, Vol. 28, pp. 289-315.

Spender, J. (1989), Industry recipes. Oxford: Basil Blackwell.

Stahl, G. and Voigt, A. (2008), "Do cultural differences matter in mergers and acquisitions? A tentative model and examination”, Organization Science, Vol. 19, pp. 160-176.

Steigenberger, N. (2017), "The challenge of integration: A review of the M\&A integration literature", International Journal of Management Reviews, Vol. 19, pp. 408-431.

Stensaker, I., Falkenberg, J. and Gronhaug, K. (2008), "Implementation activities and organizational sensemaking", Journal of Applied Behavioral Science, Vol. 44, pp. 162185.

Teece, D.J., Pisano, G. and Shuen, A. (1997), "Dynamic Capabilities and Strategic Management”, Strategic Management Journal, Vol. 18, pp. 509-533.

Teece, D. J. (2012), “Dynamic capabilities: Routines versus entrepreneurial action”, Journal of Management Studies, Vol. 49, pp. 1395-1401.

Uzelac, B., Bauer, F., Matzler, K. and Waschak, M. (2016), "The moderating effects of decision-making preferences on M\&A integration speed and performance", International Journal of Human Resource Management, Vol. 27, pp. 2436-2460:

Van Leeuwen, E., van Knippenberg, D. and Ellemers, N. (2003), "Continuing and changing group identities: The effects of merging on social identification and ingroup bias", Personality and Social Psychology Bulletin, Vol. 7, pp. 359-374.

Vermeulen, F. and Barkema, H. (2001), "Learning through acquisitions", Academy of Management Journal, Vol. 44, pp. 457-476.

Vester, J. (2002), "Lessons learned about integrating acquisitions", Research Technology Management, Vol. 45, pp. 33-41. 
Volberda, H. (1996), "Toward the flexible form: How to remain vital in hypercompetitive environments", Organization Science, Vol. 7, pp. 359-374.

Wan, W. and Yiu, D. (2009), "From crisis to opportunity: Environmental jolt, corporate acquisitions, and firm performance", Strategic Management Journal, Vol. 30, pp. 791-801.

Winter, S. (2000), "The satisficing principle in capability learning", Strategic Management Journal, Vol. 21, pp. 981-996.

Winter, S. (2003), "Understanding dynamic capabilities", Strategic Management Journal, Vol. 24, pp. 991-995.

Wright, P. and Snell, S. (1998), "Toward a unifying framework for exploring fit and flexibility in strategic human resource management", Academy of Management Review, Vol. 23, pp. 756-772.

Zajac, E., Kraatz, M. and Bresser, R. (2000), "Modeling the dynamics of strategic fit: A normative approach to strategic change”, Strategic Management Journal, Vol. 21, pp. 429453.

Zhou, Y. (2011), "Synergy, coordination costs, and diversification choices", Strategic Management Journal, Vol. 32, pp. 624-639.

Zollo, M, and Singh, H. (2004), "Deliberate Learning in Corporate Acquisition: Postacquisition Strategies and Integration Capabilities in U.S. Bank Mergers", Strategic Management Journal, Vol. 25 No. 13, pp. 1233-1256.

Zollo, M. (2009), "Superstitious learning with rare strategic decisions: Theory and evidence from corporate acquisitions", Organization Science, Vol. 20, pp. 894-908. 
Figure 1. Framework of Integration Flexibility's Influence on Acquisition Performance

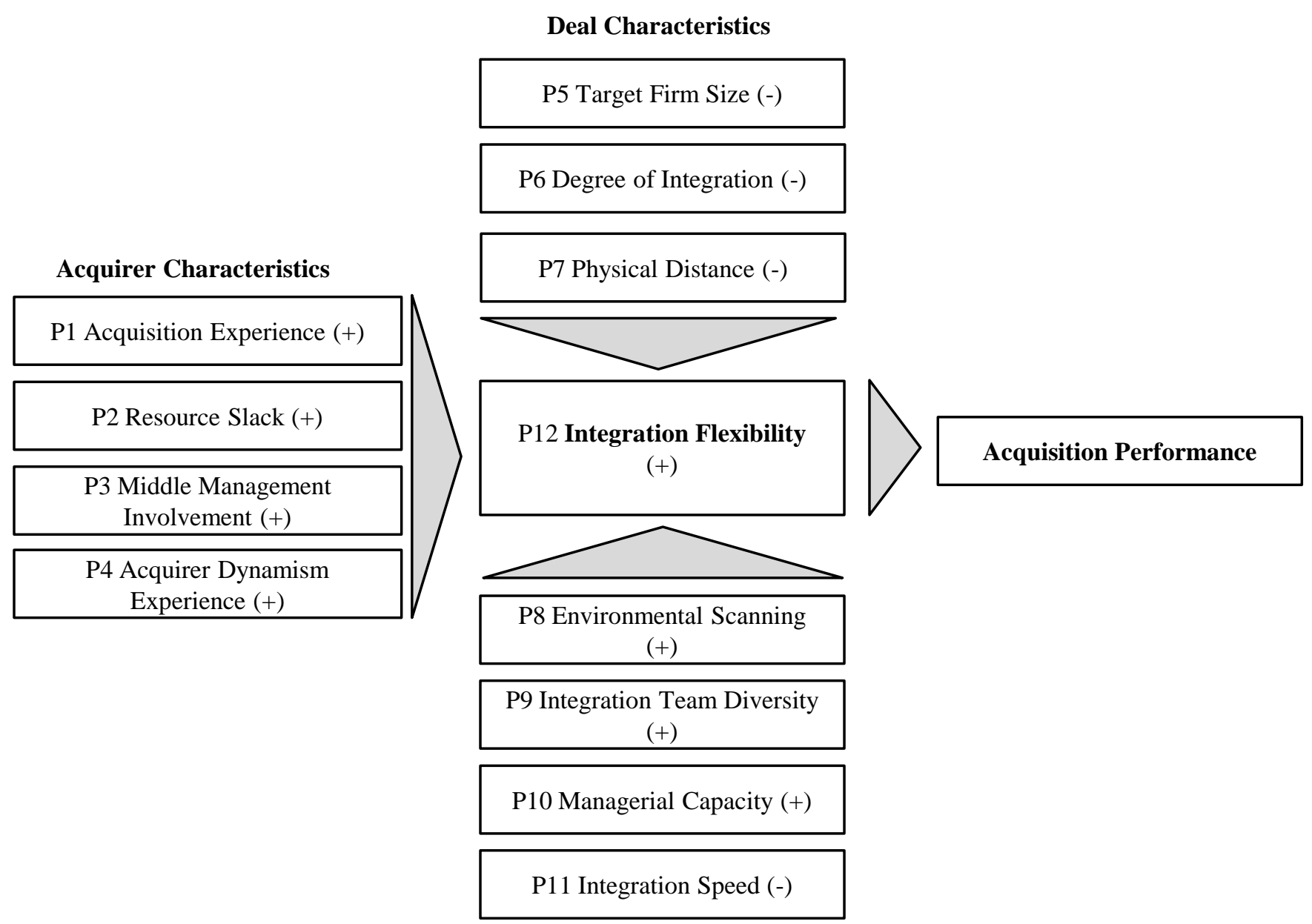

Integration Management 